\title{
ИДИОПАТИЧЕСКИЙ СИНДРОМ СЛАБОСТИ СИНУСОВОГО УЗЛА
}

\author{
С.Ю. Никулина, В.А. Шульман, А.А. Чернова \\ Красноярская государственная медицинская академия
}

\author{
Идиопатический синдром слабости синусового узла \\ С.Ю. Никулина, В.А. Шульман, А.А. Чернова \\ Красноярская государственная медицинская академия
}

Цель. Оценить изменение наследственной отягощенности синдрома слабости синусового узла в семьях больных СССУ и вариабельность сердечного ритма (ВСР) у больных СССУ.

Материал и методы. Обследованы 33 семьи, в которых наблюдались случаи первичного наследственного СССу. Всем пробандам и их родственникам в 1990 и в 2005-2006 проводили клиническое исследование, холтеровское мониторирование ЭКГ, атропиновую пробу, чреспищеводную стимуляцию левого предсердия, ЭхоКГ, велоэргометрию. Кардиоритмография выполнялась у больных СССУ только в $2005-2006$. Результаты. За 15 лет зарегистрирован прирост семейной отягощенности по СССУ с 31 до 35\%. При этом обнаружен достоверный прирост больных СССУ среди дочерей (с 50 до 71\%), племянников (с 33 до 50\%) и племянниц (с 0 до 20\%). Анализ ВСР показал преобладание тонуса симпатической нервной системы у больных СССУ.

Заключение. Показан рост наследственной отягощенности СССУ преимущественно по женской линии. Анализ ВСР может использоваться для диагностики СССУ.

Ключевые слова: синдром слабости синусового узла, наследственная отягощенность, ген натриевого сердечного канала SCN5A, вариабельность сердечного ритма

РФК 2007;5:58-61

Idiopathic sick sinus syndrome

S.Y. Nikulina, V.A. Schulman, A.A. Chernova

Krasnoyarsk State Medical Academy

Aim. To evaluate changes in hereditary burden of sick sinus syndrome (SSS) in families of patients with SSS and assess heart rate variability (HRV) in patients with SSS.

Results. 33 families of patients with SSS were examined. Clinical study, ECG-Holter monitoring, atropine test, transesophageal left atrial stimulation, echocardiography, veloergometry were fulfilled in all probands and their relatives in 1990 and 2005-2006. Cardiorhythmography was done in patients with SSS only in 2005-2006.

Results. Increase in hereditary burden with SSS from 31 to 35\% is registered during 15 years. Significant growth of patients with SSS was observed among daughters (from 50 to $71 \%$ ), nephews (from 33 to 50\%) and nieces (from 0 to $20 \%$ ). HRV analysis shows prevalence of sympathetic system activity in patients with SSS.

Conclusion. Growth of hereditary burden with SSS especially among female relatives is shown. HRV analysis can be used for SSS diagnostics.

Key words: sick sinus syndrome, hereditary burden, heart sodium channel gene SCN5A, heart rate variability

Rational Pharmacother. Card. 2007;5:58-61

Более четырех десятилетий назад синдром слабости синусового узла (СССУ) был выделен в самостоятельную нозологическую единицу.

В кардиологическом центре МУЗ ГКБ №20 г. Красноярска на кафедре внутренних болезней №1 15 лет назад на обширном клиническом материале были установлены характер наследования СССУ, связь этого заболевания с полом, определенный возрастной пик заболевания, его соматометрические предикторы.

Выявление новых случаев заболевания в семьях, например, у родственников, которые раньше не отмечали наличие заболевания, или у новых членов семей (детей, внуков) позволило бы подтвердить наследственную детерминированность СССУ, определить генетический груз данной патологии в семьях.

Наиболее диагностически значимым и эффективным методом диагностики СССУ считается чреспищеводная стимуляция левого предсердия (ЧПСЛП). В последние годы появился новый метод исследования кардиологических больных - кардиоритмография.
Неинвазивность, доступность и простота этого метода позволяет использовать его у лиц с наследственной предрасположенностью к СССУ и тем самым осуществлять раннюю диагностику этого заболевания.

Термин «sick sinus syndrome» введен в клиническую практику B. Lown в 1965 г. [1]. Русскоязычный эквивалент этого термина - синдром слабости синусового узла (СССУ) - был предложен А. Л. Сыркиным в 1970 г. [2].

Причины нарушения ритмопродуцирующей активности синусового узла можно разделить на первичные (наследственно обусловленные) и вторичные (обусловленные органическим поражением самого узла или экстракардиальными процессами).

Первые клинические описания болезни синусового узла появились в начале 20 века. A. Cohn, T. Lewis в 1912 г. [3] описали больного с пароксизмами мерцания предсердий, которые заканчивались асистолией с приступами Морганьи - Адамса - Стокса. В 1916 г. S. A. Lewine [4] описал синоатриальную блокаду (САБ). D. Short и др. в 1954 г. выделили синдром бради-та- 
хикардии (СБТ). Согласно данным С. Thery и соавт. [5], у 104-х из 111-ти больных, прижизненно страдающих СССУ, были обнаружены фиброз синусового узла и дегенеративные изменения предсердий неясной этиологии. У 2-х из 111 -ти больных был выявлен инфаркт миокарда.

Одно из первых сообщений о семейном узловом ритме принадлежит J.M. Васоs и соавт. [6]. Обратившийся в клинику пятидесятилетний больной и его родной брат имели на ЭКГ узловой ритм, периодически - пароксизмы фибрилляции предсердий. Больные отмечали эпизоды головокружения и слабости. У матери этих больных с детства редкий пульс, последние 20 лет на ЭКГ - пароксизмы фибрилляции предсердий, периодически полная блокада левой ножки пучка Гиса (ПБЛНПГ) и желудочковая экстрасистолия. Авторы предположили, что такие нарушения ритма сердца обусловлены генетическим дефектом, передающимся аутосомно-доминантным путем с высокой пенетрантностью.

R. Rokseth с соавт. (1970) [7] наблюдали 14 больных с САБ, сопровождающейся пароксизмальной тахикардией, которым был имплантирован кардиостимулятор. У 2-х больных заболевание было семейным. A. F. Mackintosh и D. A. Chamberlain (1979) [8] описали семью, в которой оба родителя и двое их детей страдали болезнью синусового узла. R. Spellberg [9] наблюдал семью, где в трех поколениях прослеживалось наследование синдрома больного синуса. B. Livesley c соавт. [10] наблюдали семью, в которой синоатриальные нарушения были выявлены у 50-летнего отца и двух его детей ( 14 и 18 лет). Согласно данным A.J. Fairfax и др. (1976) [11], у 2-х из 100 больных с синоатриальной патологией заболевание носило семейный характер. D. Caralis, P.J. Varghese [12] наблюдали семью, три члена которой страдали дисфункцией синусового узла, детально описали клинические и ЭКГ-признаки данного синдрома. В том же году А. Nordenberg, P.J. Varghese [13] описали двух сестер в возрасте 14 и 25 лет с признаками СССУ. У одной больной в течение пяти лет бо- лезнь прогрессировала от синусовой брадикардии до «ареста синусового узла» с дальнейшим развитием различных типов эктопических аритмий. У ее сестры в возрасте 23 лет развились "молчание" предсердий и церебральная эмболия. J.C. Beer и B. Meithae [14] также описали семейную форму болезни синусового узла (у 3-х из 4-х детей этой семьи).

СССУ оказался сцепленным с мутациями гена натриевого сердечного канала (SCN5A) [15]. Обнаружены 3 вида мутаций этого гена: миссенс - мутации (T2201, P1298L, G1408R, R1632H), внутрирамочная делеция (del F1617), нонсенс - мутация (R1623X).

У 10 детей из 7 семей диагноз СССУ был поставлен в первые 10 лет жизни, причем у четырех из них - еще во внутриутробном периоде. Пятеро детей из трех семей оказались гетерозиготными носителями мутаций гена SCN5A. Мутации были обнаружены в 5 различных аллелях этого гена. Установлен аутосомно - рецессивный тип наследования СССУ у этих больных.

В основе СССУ может лежать также патология гена HCN4, локализованного на хромосоме 15. Нарушение работы ионных каналов приводит к замедлению скорости спонтанной деполяризации и уменьшению частоты синусового ритма.

\section{Цель исследования}

Оценить прирост наследственной отягощенности синдрома слабости синусового узла в семьях г. Красноярска и характер временных показателей вариабельности сердечного ритма (ВСР) у больных с СССУ.

\section{Материал и методы}

Из базы данных кафедры терапии №1 были отобраны 33 семьи с первичным, наследственным СССУ. Из этих 33-х семей были взяты данные клинико - инструментального исследования 9 пробандов и 42 их родственников I, II, III степени родства. Среди пробандов было 5 женщин и 4 мужчин, средний возраст составил $58 \pm 0,18 л е т$. У 2 -х пробандов был имплантирован электрокардиостимулятор (ЭКС) в связи с декомпенсиро-

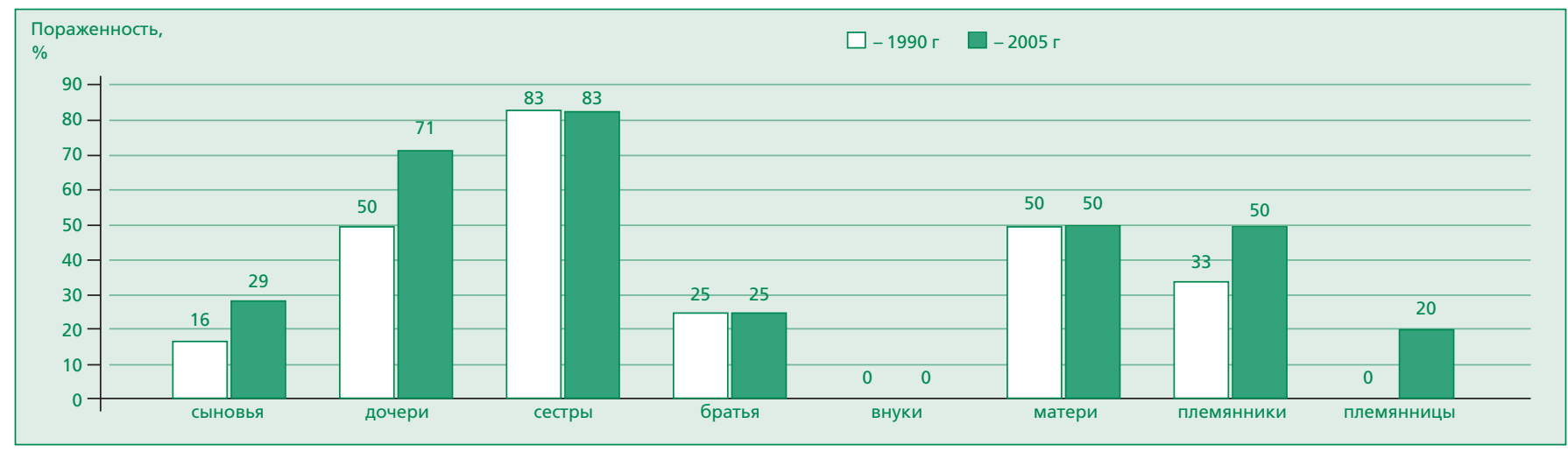

Рисунок 1. Семейная агрегация синдрома слабости синусового узла 


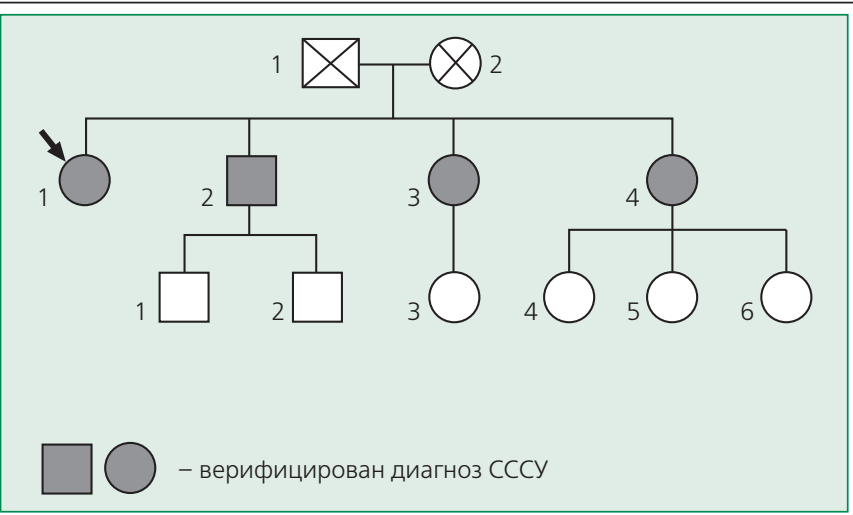

Рисунок 2. Родословная семьи В. (1990 г.)

Таблица. Показатели кардиоритмографии у больных сССУ и их здоровых родственников

\begin{tabular}{|c|c|c|c|}
\hline Показатель & $\begin{array}{c}\text { CCCY } \\
(n=13)\end{array}$ & $\begin{array}{c}\text { Здоровые } \\
\text { родственники } \\
(n=16)\end{array}$ & $p$ \\
\hline CKOI & $0,06 \pm 0,04$ & $0,06 \pm 0,03$ & $>0,05$ \\
\hline CKO II & $0,08 \pm 0,04$ & $0,06 \pm 0,03$ & $>0,05$ \\
\hline CKO III & $0,08 \pm 0,04$ & $0,07 \pm 0.04$ & $>0,05$ \\
\hline Индекс напряжения I & $71,33 \pm 49,1$ & $240,77 \pm 389,75$ & $>0,05$ \\
\hline Индекс напряжения II & $74,11 \pm 73,97$ & $197,31 \pm 255,8$ & $>0,05$ \\
\hline Индекс напряжения III & $43,67 \pm 24,58$ & $124,69 \pm 154,39$ & $>0,05$ \\
\hline $\begin{array}{l}\text { Коэффициент корреляь } \\
\text { быстрых волн к } \\
\text { пневмотахограмме I }\end{array}$ & $16,25 \pm 16,55$ & $36 \pm 2$ & $<0,05$ \\
\hline $\begin{array}{l}\text { Коэффициент корреляь } \\
\text { быстрых волн к } \\
\text { пневмотахограмме ІІ }\end{array}$ & \multicolumn{3}{|c|}{ Коэффициент корреляции } \\
\hline $\begin{array}{l}\text { Коэффициент корреляь } \\
\text { быстрых волн к } \\
\text { пневмотахограмме III }\end{array}$ & & \multicolumn{2}{|c|}{ Коэффициент корреляции } \\
\hline pRR 50 I & $28,33 \pm 22,45$ & $14,77 \pm 18,51$ & $>0,05$ \\
\hline pRR $50 \|$ & $17,00 \pm 17,39$ & $7,54 \pm 8,37$ & $>0,05$ \\
\hline pRR 50 III & $25,89 \pm 21,68$ & $14,54 \pm 17,00$ & $>0,05$ \\
\hline \multicolumn{4}{|c|}{$\begin{array}{l}\text { CKO (средне-квадратичное отклонение) - показатель регуляции сер- } \\
\text { дечного ритма парасимпатической нервной системы - в норме соста- } \\
\text { вляет 0,05 - 0,07; индекс напряжения является симпатическим } \\
\text { показателем, его норма - 80-150 у.е.; коэффициент корреляции (от- } \\
\text { ношение быстрых волн в пневмотахограмме; в норме должен быть } \\
\text { более 20\%); RR } 50 \text { - число RR - интервалов, отличающихся от сосед- } \\
\text { них более чем на } 50 \text { мс; pRR } 50 \text { - отношение RR50 к общему числу } \\
\text { RR интервалов, в норме превышает } 5 \text {. }\end{array}$} \\
\hline
\end{tabular}

ванным вариантом СССУ. Среди 42-х родственников было 18 мужчин и 24 женщины (средний возраст 48土0,15 лет).

К 2006 г. из 9 пробандов 1 умер. Число родственников I, II и III степени родства возросло до 51 (4 умерли, дополнительно были обследованы 13 родственников).

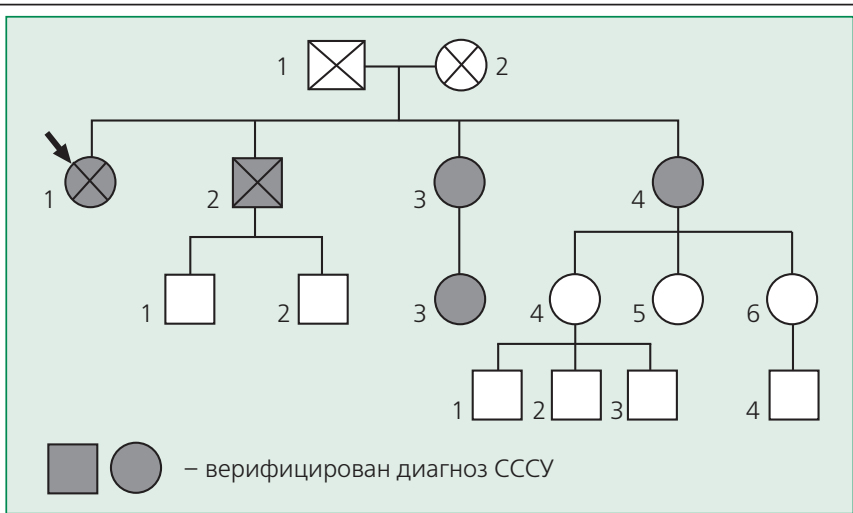

Рисунок 3. Родословная семьи В. (2005 г.)

Всем пробандам и их родственникам в 1990 и в 2005-2006 г.г. проводили клиническое исследование, ЭКГ, холтеровское мониторирование ЭКГ, атропиновую пробу, чреспищеводную стимуляцию левого предсердия, ЭхоКГ, велоэргометрию, кардиоритмографию. Последний метод исследования выполнялся у больных только в 2005-2006 г.г.

Статистическую обработку материала проводили с помощью программы «Statistica». Для сравнения полученных средних показателей применялся критерий шера - Стьюдента; для сравнения величин, выраженных в процентах, использовали критерий $\chi^{2}$.

\section{Результаты и обсуждение}

Частота СССУ в семьях в 1990 г. составляла 31\%, что значимо превышает частоту этой патологии в популяции г. Красноярска $(0,0296 \%)$ и свидетельствует о генетической детерминированности этого синдрома. В 2005 - 2006 г.г. семейное накопление заболевания достигло 35\% ( 18 больных СССУ из 51). Выявлено 5 новых случаев латентного варианта СССУ (2 дочери, сын, племянник и племянница).

В семьях пробандов с СССУ к 2005 г. отмечен достоверный прирост данной патологии среди сыновей (с $16 \%$ до 29\%), дочерей (с 50\% до 71\%), племянников (с 33\% до 50\%) в 2005 году и племянниц (с 0\% до 20\%) (рис.1). Наибольшее количество случаев СССУ регистрировалось среди лиц женского пола (дочери - до 71\%, сестры - до 83\%).

В 9 семьях среди 13 родстенников с компенсированным в 1990 г. СССУ за 15 лет наблюдения только у 1 -го из них произошел переход в декомпенсированный вариант СССУ. У этой родственницы в клинической картине заболевания появились признаки церебральной ишемии: головокружения, обмороки, при чреспищеводной стимуляции левого предсердия - паузы до 4-х с после медикаментозной вегетативной блокады (МВБ).

За 15 -летний период 1 пробанд и 4 больных родственника умерли. Причина смерти, по данным справок, выданных семьям, - острая коронарная недостаточность (у четверых). Однако, учитывая, что все эти па- 
циенты были с компенсированным вариантом СССУ, вероятнее всего, причины смерти их не были связаны с этой патологией. У 1 пробанда с декомпенсированным вариантом СССУ развилась хроническая форма фибрилляции предсердий. Таким образом, при анализе особенностей течения СССУ обращало на себя внимание чрезвычайно медленное его прогрессирование.

В качестве примера семейной отягощенности СССУ приводим одну из родословных обследуемых нами семей с этой патологией (рис. 2).

У женщины 58 лет, её брата 54 лет и 2-х сестер 50 и 48 лет с помощью клинико-инструментального обследования в 1990 г. верифицирован диагноз СССУ. Давность заболевания у них не установлена. Первые жалобы, которые можно связать с СССУ, появились у всех больных после достижения 50-летнего возраста. У одной из сестер к этому времени развилась гипертоническая болезнь; у одного из братьев гипертоническая болезнь к моменту обследования сочеталась с ИБС. Учитывая явно наследственный характер СССУ в данной семье, есть основание полагать, что ИБС, гипертоническая болезнь и СССУ развивались у больных независимо друг от друга. На предыдущих ЭКГ регистрировалась синусовая брадикардия.

\section{Литература}

1. Lown B. Electrical conversion of cardiac arrhythmias. J Chron Dis 1965;18:899-904.

2. Сыркин А. Л., Недоступ А. В., Маевская И. В. Электроимпульсное лечение в клинике внутренних болезней. М.: Медицина; 1970.

3. Cohn A., Lewis T. Auricular fibrillation and complete heart block: a description of a case of Adams-Stokes syndrome including the post-mortem examination. Heart 1912-1913;4:15-32.

4. Levine S. A. Observation on sinoauricular heart block. Arch Intern Med 1916;17:153-75.

5. Thery C., Cosselin B., Lekieffre J., Warembourg H. Pathology of sinoatrial node. Correlation with electrocardiographic findings in 11 patients. Am Heart J 1977;93(6):735-40.

6. Bacos J. M., Eagain J. T., Orgain E. S. Congenital familial nodal rhythm. Circulation 1960;22:887-95.

7. Rokseth R., Hatle L. Prospective study on the occurrence and management of chronic sinoatrial disease with follow up. Brit Heart J 1974;36:582-7
K 2005 году пробанд, её брат и сестра умерли, причина смерти - острая коронарная недостаточность. К этому времени диагностирован новый случай СССУ (латентный вариант) у племянницы пробанда 50 лет, очевидно, достигшей определенного возрастного пика в онтогенезе (рис. 3).

У всех больных с СССУ отношение числа быстрых волн к пневмотахограмме были менее необходимого показателя (20\%). Это свидетельствует о преобладании тонуса симпатической нервной системы и снижении вариабельности сердечного ритма (табл.).

\section{Заключение}

За 15 лет зарегистрирован прирост семейной отягощенности по СССУ с $31 \%$ до 35\%; при этом обнаружен достоверный прирост больных СССУ среди дочерей с $50 \%$ до 71\%, среди племянников - с 33 \% до 50\%, племянниц - с 0\% до 20\%, а также подтверждено преобладание наследования СССУ по женской линии. Анализ вариабельности сердечного ритма может использоваться для диагностики СССУ. Следует отметить чрезвычайно медленное прогрессирование семейного СССУ.

8. Mackintosh A.F., Chamberlain D.A. Sinus node disease affecting both parents and both children. Eur J Cardiol 1979;10(2):117-22.

9. Spellberg R. D. Familial sinus node disease. Chest 1971;60(3):246-51

10. Livesley B., Caralis P. F., Oram S. Familial sinoatrial disorder. Brit Heart J 1972;34:668-70.

11. Disertori M, Guarnerio M, Vergara G, et al. Familial endemic persistent atrial standstill in a small mountain community: review of eight cases. Eur Heart J 1983;4:354-61.

12. Caralis G., Varghese P. Familial sinoatrial dysfunction. Increased vagal tone a possible etiology. Br Heart J 1976;9:956-7.

13. Nordenberg A, Varghese PJ, Nugent EW. Spectrum of sinus node dysfunction in two siblings. Am Heart J. 1976;91(4):507-12.

14. Beer J., Meithae B., Ducam H. et al. Maladie du sinas a propos dune observation. Coeur 1976;7(2):233-45.

15. Benson D. W. Genetics of atrioventricular conduction disease in humans. Anat Rec A Discov Mol Cell Evol Biol 2004;280(2):934-9.

16. Shulze-Bahr E., Neu A., Friederich P., et al. Pacemaker channel dysfunction in a patient with sinus node disease. J Clin Invest 2003;111:153745. 